\title{
A ressignificação do espaço público de Porto Alegre a partir da apropriação efêmera da cidade
}

\author{
Roberta Krahe Edelweiss \\ Centro Universitário Ritter dos Reis - UniRitter, Porto Alegre. \\ Contato: robertaedelweiss@gmail.com
}

\section{Mauricio Ricardo Cabas Garzon}

Universidad de la Costa (CUC), Barranquilla, Colômbia.

Contato: mauricio@cabasgarzon.com

\section{Introduçáo}

O entendimento da cidade como um organismo vivo é capaz de colocar à prova as hipóteses lançadas pelo planejamento urbano, validando tais hipóteses ou rechaçando-as. É a partir do uso da cidade que se faz possível, portanto, uma compreensão da evolução de seu significado ao longo do tempo. As possibilidades de reunião entre cidadãos é o que atribui a um contexto urbano sua identidade. E é nos espaços públicos onde esse encontro ocorre. Sendo assim, os espaços públicos têm grande responsabilidade como palco do diálogo entre cidadáos. A apropriação efêmera do espaço urbano pode ser entendida como uma experimentação de hipóteses ou como um modo flexível de uso da cidade. Conforme o autor de A cidade na História:

Antes da cidade, houve a pequena povoação, $o$ santuário a aldeia; antes da aldeia, o acampamento, o esconderijo, a caverna, o montão de pedras; e antes de tudo isso houve uma certa predisposição para a vida social que o homem compartilha, evidentemente, com diversas outras espécies animais. (MUMFORD, 1995, p.11).

Mumford retrata a cidade como resultado do habitar. Já o habitar conforme HEIDEGGER (1994) entende a cidade e as edificaçóes como resultado de um gesto ou de uma necessidade criados pela sociedade. $\mathrm{O}$ uso da cidade no tempo é capaz de conformar novas transformaçôes a partir das necessidades do habitar e, portanto, se faz passível de ressignificação. $\mathrm{O}$ entendimento da sociedade como elemento motivador das transformações urbanas, bem como o patrimônio imaterial construído na cidade, são o foco principal deste trabalho.

Os espaços multifuncionais da cidade devem ser entendidos na contemporaneidade através de sua multiplicidade funcional e, por consequência, de sua multiplicidade de significados sociais. A partir do cenário contemporâneo, o artigo centra-se no significado atual do espaço público no cenário urbano. Como base teórico-metodológica recorre-se à teoria do lugar proposta pelo arquiteto e teórico da arquitetura Josep Muntañola e à aplicação da narrativa ao campo de Arquitetura e Urbanismo elaborada pelo filósofo e antropólogo Paul Ricoeur. No primeiro caso, trata-se do entendimento da construção da cidade como um processo dialógico onde todos os elementos são contribuintes da 
construção do lugar; e, no segundo, de uma estrutura de interpretação do contexto urbano a partir de sua complexidade espaço-temporal. Nesse sentido, o artigo aborda a apropriação efêmera da cidade contemporânea, entendida como ato de habitar e construtora de lugar, portanto, atribuída de significado social.

Compreendendo tanto a vitalidade da cidade a partir de seus processos de transformação, quanto a construção de uma identidade a partir de açóes da sociedade civil constituintes de valores de memória, a abordagem centra-se nos eventos efêmeros de apropriaçáo do espaço público realizados e aplicados ao estudo de caso de Porto Alegre. Os objetos abordados no artigo são as feiras de bairro e os movimentos sociais de ocupaçáo dos parques urbanos, ruas e calçadas. Esses eventos podem ser compreendidos por uma apropriação efêmera da cidade e têm importante significado como parte integrante da complexidade urbana. O artigo, nesse sentido, aborda o estudo de caso da ressignificação do espaço público aplicado à cidade de Porto Alegre.

\section{A teoria do lugar e o emprego da narrativa para a interpretaçáo do espaço público}

Com base em uma visão interdisciplinar, a Topogênesis, ou Arquitetura como Lugar, busca compreender a construção de lugares a partir de um ponto de vista arquitetônico. Para tal, Josep Muntańola propóe o uso de outras disciplinas como aporte instrumental. Nessa busca, são válidas contribuiçốes dos campos da Ética, da Estética e da Ciência. MUNTAÑOLA (2007, p 136) define a Topogênesis como "o estudo do desenvolvimento da arquitetura, considerada sempre como lugar habitado, desde sua tripla e simultânea natureza dialógica: estética, científica e política”.
[...] um padrão de significados incorporados nos simbolos, o qual é transmitido historicamente, num sistema de concepçóes herdadas, expressas nas formas simbólicas por meio das quais os humanos comunicam, perpetuam e desenvolvem seu conhecimento acerca da vida e de suas atitudes diante dela. (GEERTZ, 1978, p. 66).

A valorização da identidade local, entendida como manifestação cultural por parte da sociedade civil, apresenta-se através da apropriação do espaço público. Eventos efêmeros tomam espaço no contexto urbano e geram lugares de manifestação de cultura, preservação de memória e construção de identidade.

Nesse sentido, fica clara a relação indivisível entre o patrimônio imaterial e o meio físico. $\mathrm{O}$ caso de apropriaçóes efêmeras como bem intangível coloca-se como um importante desafio para a administração pública em atuar em prol da preservação e construção de memória cultural. A ressignificação de espaços onde ocorrem manifestaçóes culturais é um importante desafio também para o poder público, cuja responsabilidade é de salvaguarda da memória cultural.

Conforme supracitado, é importante ressaltar a compreensão da cidade a partir de um sistema de relaçôes, entendendo-a através de seu contexto e em sua complexidade, e atentando para a relevância das interaçôes entre partes, lugares, objetos construídos, culturas e técnicas. Trata-se, assim, de compreender o tecido urbano como um conjunto que abriga obras edificadas pertencentes à memória coletiva e que, isoladas ou náo, por sua vez fazem parte de uma totalidade complexa que representa fatos urbanos, constituindo o seu patrimônio cultural. Dessa maneira, a leitura de cada tempo considera todos os aspectos postos em diálogo, como por exemplo, as vozes de memória histórica, políticas públicas, interesses privados ou as vozes do ativismo urbano. 
3. Espaço público e eventos de apropriação efêmera em Porto Alegre - reconhecimento e diálogo entre sociedade civil e poder público

Porto Alegre tem apresentado, nas últimas décadas, uma tradição de participação cidadã. Desde 1989, durante o mandato do prefeito Olívio Dutra (Partido dos Trabalhadores/PT), com o projeto do Orçamento Participativo - cuja metodologia consiste em considerar a sociedade como parcela de decisão nas votaçóes das plenárias do governo municipal —, a capital se constitui em um modelo de construção de diálogo entre os agentes público e privado e a sociedade civil. O capital humano, no caso de Porto Alegre, tem forte atuação na participação cidadá, considerando os processos colaborativos.

Com base no pressuposto de que as transformaçóes urbanas são uma resposta às transformaçôes sociais, sejam elas locais ou globais, é relevante a consideração dos atuais movimentos sociais urbanos como os ocorridos em Porto Alegre. $\mathrm{Na}$ atualidade, a participação da sociedade civil porto-alegrense nos processos decisórios tem se dado a partir da manifestação em massa, com forte presença de redes sociais e formatos de coletivos urbanos.

O espaço público exerce papel fundamental como palco da vida urbana. É no espaço público que as práticas sociais têm oportunidade para acontecer. As praças, como espaços de permanência e de acontecimentos sociais, têm papel estruturador na identidade da cidade: são lugares de convívio social e também de manifestação da cultura. Porto Alegre apresenta uma relaçáo direta entre atuação da sociedade civil a partir de movimentos sociais e o espaço público. Nesse sentido, a capital é cenário de apropriação efêmera do espaço público. Essa apropriação se dá não somente por iniciativas da sociedade civil, mas, também, por iniciativas do poder público. A partir de exemplos de eventos efêmeros de apropriação do espaço público realizados em Porto Alegre, com o consequente reconhecimento pelo poder público e diálogo entre agentes, é possível discutir o significado contemporâneo do espaço público.

A partir dos exemplos a seguir, de atuação dos movimentos sociais, coletivos urbanos e das feiras orgânicas, é possível detectar, além da apropriação efêmera do espaço público, no caso de Porto Alegre, a complexidade expressa a partir da relação dialógica entre os agentes construtores da cidade. A relação de diálogo entre poder público e sociedade civil em cada exemplo é diferente, sendo questáo relevante as transformaçóes sociais e a apropriação efêmera do espaço como resultantes do habitar contemporâneo.

As manifestaçóes de junho de 2013, em Porto Alegre, tomaram potencial espaço nas praças e grandes avenidas da cidade (Figura 1). A geografia do movimento afirma a existência de uma 'centralidade' entendida como espaço democrático de atuação. A rota das manifestações tem por principais pontos referenciais a área central, compreendendo os espaços públicos da Praça da Matriz, diante do Palácio do Governo, e do Largo dos Açorianos, diante da prefeitura e grandes avenidas.

O desenho da atuaçáo do movimento denota a importância do espaço público como espaço de manifestação. No exemplo de Porto Alegre, as

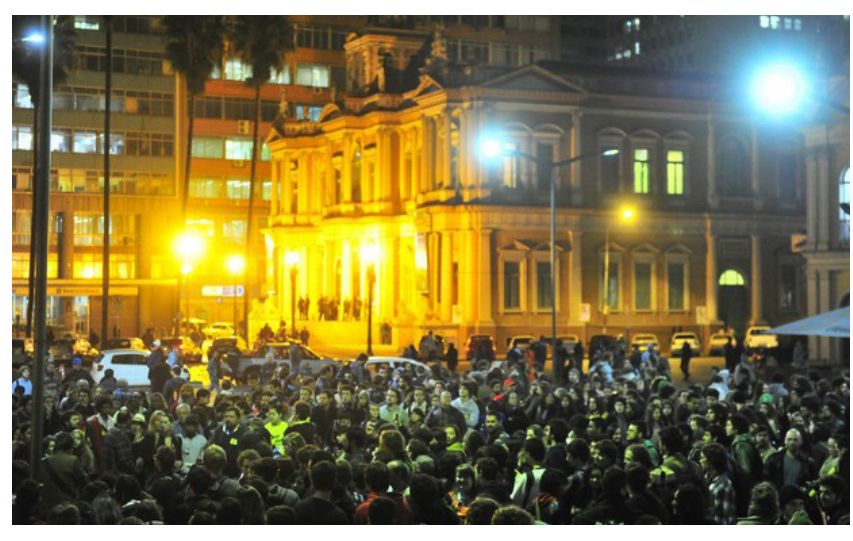

Figura 1: Manifestaçôes de junho em Porto Alegre diante da Prefeitura 


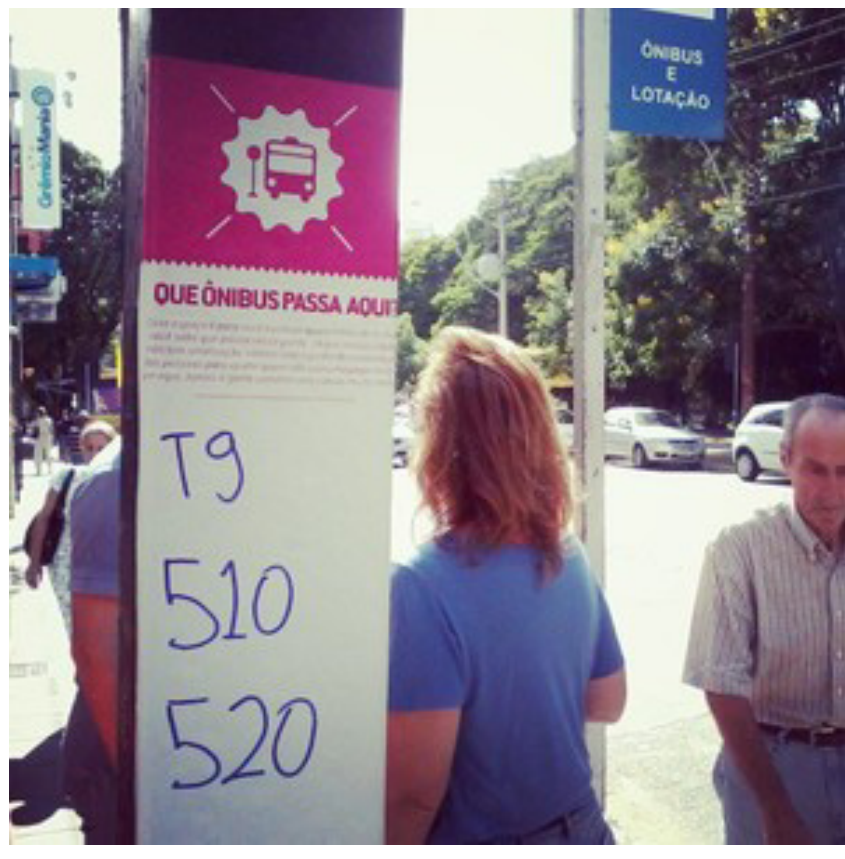

Figura 2: Projeto "Que ônibus passa aqui?”

manifestaçóes, surgidas das redes sociais, reafirmam o protagonismo desses espaços que, historicamente, já foram palco de diálogo entre sociedade civil e poder público, e reconhecem a existência de centralidades físicas na organização social e política urbana.

O segundo exemplo de atuação da sociedade civil é o projeto do coletivo Shoot the Shit (2016) "Que ônibus passa aquil, que consiste em colar adesivos nas paradas de ônibus para que seus usuários os preencham com informaçóes sobre a rede de transporte coletivo (Figura 2). Nesse caso, observa-se a melhoria das condiçóes de habitabilidade oferecidas pelo poder público a partir da colaboração da sociedade. O projeto apresentase como uma crítica à falta de informaçáo aos usuários por parte do transporte público e estimula a construção coletiva por parte dos usuários.

Também do coletivo Shoot the Shit, o projeto "Paraíso do Golfe" consistiu na elaboração de um vídeo humorado que revelou as más condições das vias de Porto Alegre (Figura 3). O projeto transformou a malha viária em um campo de golfe e utilizou buracos em situação crítica como uma analogia aos buracos de uma partida de golfe. $\mathrm{O}$ vídeo acumulou, em uma semana, mais de $80 \mathrm{mil}$ visualizaçôes e, conforme relatado na página web do coletivo, "a prefeitura resolveu tapar todos os buracos que apareciam no vídeo" (PARAÍSO DO GOLFE, 2016).

O coletivo Shoot the Shit, com início em 2010 e foco em projetos de comunicação, tem atuação no território urbano porto-alegrense e sua missão é gerar valor para as pessoas, deixando um legado positivo para a cidade. No exemplo do vídeo "Paraíso do Golfe", observa-se o sucesso dessa iniciativa tanto por parte do coletivo quanto da atuação da sociedade através das redes sociais, que resultou no registro de mais de 80 mil visualizaçóes do protesto em uma semana. No caso do projeto "Que ônibus passa aqui", observa-se o papel da sociedade como construtora direta da melhoria no espaço público. De diferentes maneiras, a atuação do coletivo tem como resultado de seus projetos a melhoria do espaço público, colocando o usuário como o foco principal de sua intervenção e promovendo açóes que tenham o envolvimento da coletividade como agentes de transformação.

Já as Serenatas Iluminadas (2016), encontros organizados a partir das redes sociais, têm por propósito ocupar os parques e redescobrir a cidade de Porto Alegre (Figura 4). Cada serenata ocorre em um lugar diferente da cidade, criando um evento de convívio social e manifestação de cultura e, dessa maneira, coletivamente em segurança. Uma vez que há insegurança no cenário noturno de Porto Alegre, se reconhece a cidade à noite, o que seria uma prática inconcebível sem a mobilização coletiva. A apropriação urbana dos espaços públicos, nesse caso, ocorre como uma solução alternativa à insegurança.

A atuação do movimento Cais Mauá de Todos, com mais de treze mil seguidores, tem por objetivo travar a construção de um shopping e de torres 


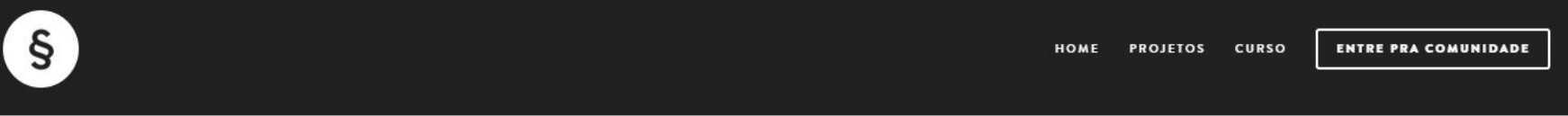

O humor transforma.

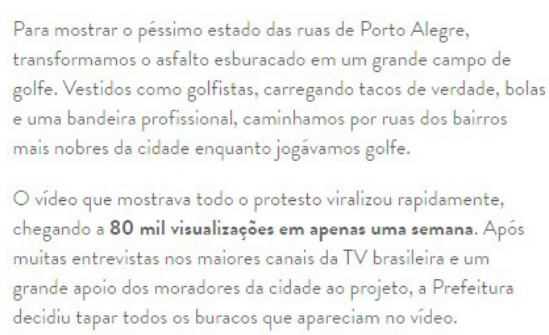

Figura 3 : Video paraiso do golfe

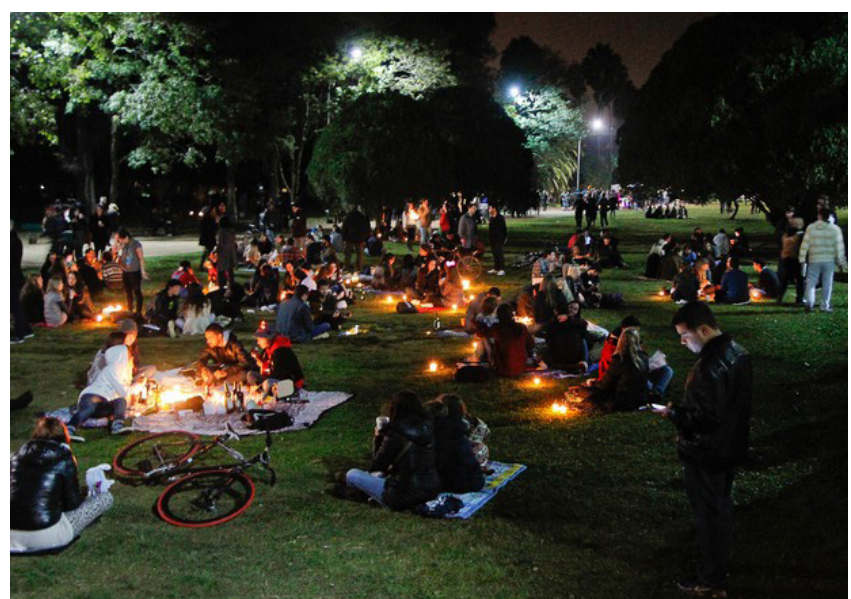

Figura 4: Serenata iluminada no Parque da Redençâa

comerciais no setor (Figura 5). O movimento atua em resposta contrária à proposta do projeto Viva Cais Mauá (2016). Em sua página no Facebook, afirma:

Porto Alegre só existe por causa do porto, que aliás dá nome à cidade. Se não fosse o porto, a capital seria Viamáo, como de fato foi. Obviamente que nós não queremos que aquela área continue abandonada e degradada. Nós queremos sim progresso e desenvolvimento, geração de empregos, tudo isso. Mas não aceitamos shopping e torres naquela área da cidade. E queremos envolver a população nessa discussão.
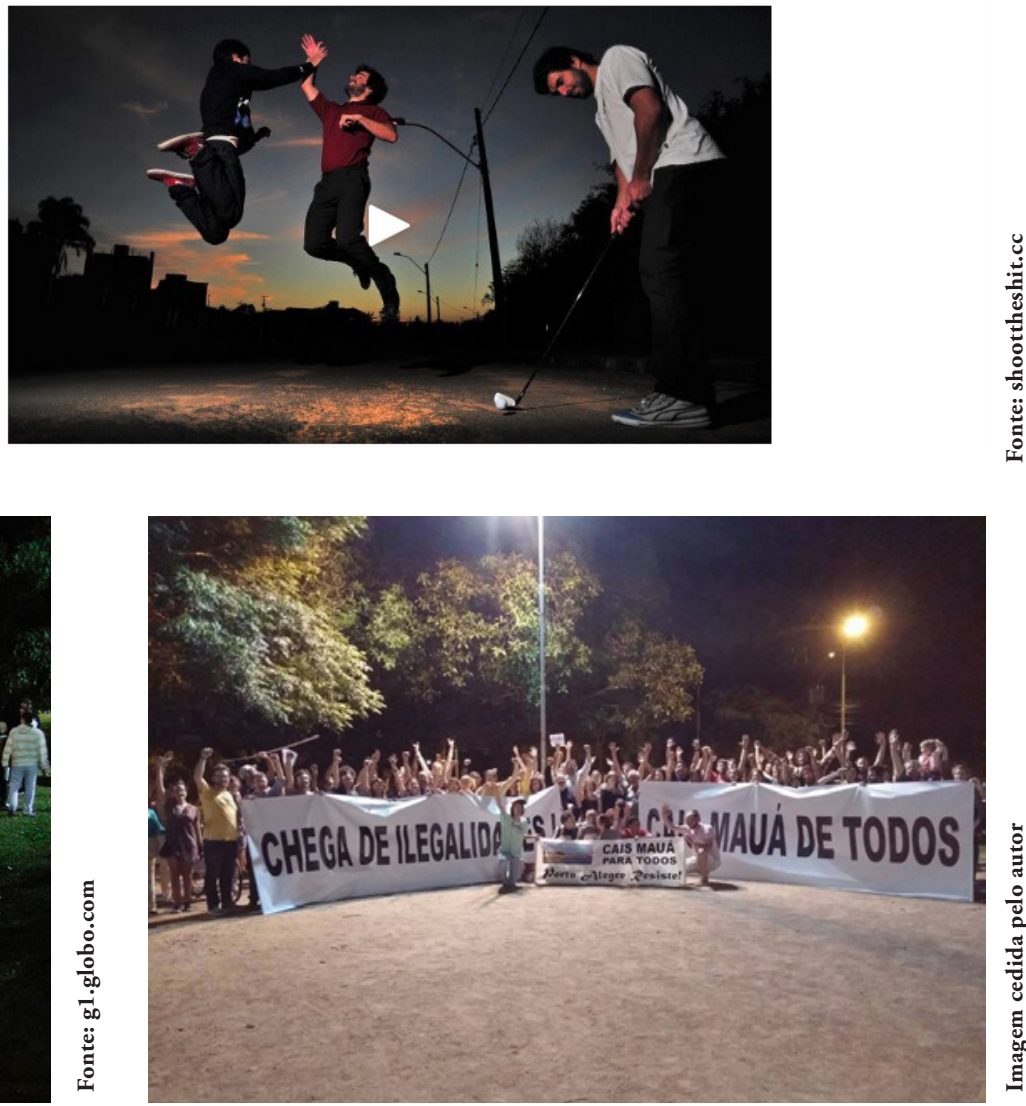

Figura 5: Movimento Cais Mauá de Todos

O exemplo do Cais Mauá demonstra a vontade de uma grande parcela da sociedade de participar e de decidir sobre os usos do espaço público. A demanda do movimento por um processo decisório democrático envolvendo a população confirma a relação afetiva dos usuários com a cidade e, portanto, justifica sua manifestação, sua apropriação e sua participação.

Por fim, as Feiras Ecológicas de Porto Alegre oferecem produtos vindos da área rural de Porto Alegre e do interior do Estado para a comercialização direta ao consumidor (Figura 6). A busca contemporânea por um modus vivendi mais sustentável nas grandes cidades tem um 


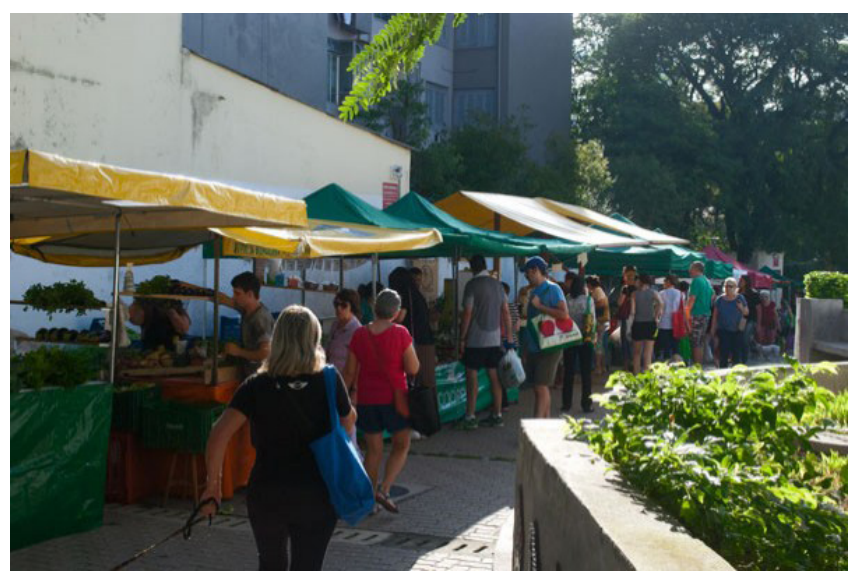

Figura 6: Feira orgânica no bairro Auxiliadora

importante pilar na cadeia da alimentação. A relação de dependência entre cidade e campo, e o reconhecimento do valor do produto saudável, comprova-se em Porto Alegre com a organização de feiras ecológicas com o apoio da prefeitura.

O espaço de apropriação das feiras orgânicas de Porto Alegre é o espaço da rua. O mapeamento dos bairros, a logística urbana e a divulgação de agenda via internet, bem como sua fiscalização, estão sob responsabilidade da prefeitura (SMIC, 2016). Entendendo que o reconhecimento do espaço efêmero impacta na dinâmica da mobilidade urbana e na estrutura social e comercial local, acredita-se que o exemplo surge do reconhecimento tanto de uma necessidade quanto de uma prática informal. O reconhecimento do espaço urbano em sua complexidade por parte do poder público, bem como a configuração da estrutura efêmera, colocam-se à prova no momento atual que, em constante releitura, vem se remodelando a partir de novas necessidades, sejam elas produtoras ou novas demandas de bairros.

\section{Conclusáo}

Os exemplos apresentados neste artigo afirmam a apropriação efêmera do espaço público na cidade de Porto Alegre. Seja por parte das manifestaçôes de junho de 2013, capazes de traçar uma geografia política da cidade; do coletivo Shoot the Shit, capaz de transformar a cidade através de incentivos à participação cidadá; das Serenatas Iluminadas, que constituem eventos de defesa à insegurança a partir da coletividade; ou por parte das feiras ecológicas, que promovem o encontro entre sociedade urbana e produtores rurais, a capital gaúcha demonstra ser um organismo vivo, onde todos os agentes têm voz e constroem a cidade.

A breve descrição desses eventos em Porto Alegre demonstra a apropriação do espaço público de maneira efêmera. Na busca pelo equilíbrio entre sociedade, poder público, aspectos ambientais e aspectos econômicos, deve ser promovido o diálogo entre todos os agentes. Nesse sentido, é importante ter em mente os entraves entre poder público e sociedade civil, uma vez que entre os agentes construtores da cidade observa-se diálogo e manifestação, como no exemplo do Cais Mauá, a partir de uma sociedade com tradiçáo participativa. Prova-se a importância do diálogo, mesmo que os processos sejam mais lentos, na construção de uma sociedade democrática.

A afirmação da cultura do lugar por parte dos usuários, configurados na apropriação urbana, integra o patrimônio imaterial de Porto Alegre. O reconhecimento e a afirmaçáo da cultura do lugar constituem, por sua vez, as transformaçóes urbanas. As diferentes atuaçóes dos coletivos, movimentos e feiras de bairro citados demonstram a construção da memória do lugar tendo como base a cultura. Essas iniciativas traçam uma perspectiva de futuro a partir da busca de uma organização entre capital humano, planejamento e incentivos. O reconhecimento de formas de apropriação do espaço e da vitalidade da cidade através de seus processos de transformação são a base para uma melhor organização social, e a sua implementação e melhoria poderão possibilitar gestão e práticas inteligentes e mais sustentáveis. 


\section{Referências Bibliográficas:}

CAIS MAUÁ DE TODOS. Disponível em: <https:// www.facebook.com/caismaua

detodos>. Acesso em: 16 mai. 2016.

GEERTZ, C. A interpretação das culturas. Rio de Janeiro: Zahar, 1978.

HEIDEGGER, M. Conferencias y artículos. In: Construir, habitar, pensar. Barcelona: Serbal, 1994. cap. 6.

MENESES, U. B. O campo do patrimônio cultural: uma revisão de premissas. In: FORUM NACIONAL DO PATRIMÔNIO CULTURAL, 1., 2009, Ouro Preto. Anais... Ouro Preto: Instituto do Patrimônio Histórico e Artístico Nacional, 2009. p. 127137.

MUMFORD, L. A cidade na história. São Paulo: Martins Fontes, 1995.

MUNTAÑOLA J. La arquitectura de la narrativa, la narrativa de la arquitectura. In: Topogénsis.

Fundamentos de uma nueva arquitectura. Barcelona: Edicions UPC, 2000. 2007.

PARAÍSO DO GOLFE. Disponível em: <http://www. shoottheshit.cc/projetos/>. Acesso em: 15 jul. 2016.

RICOEUR, P. Tiempo y narración. México: Siglo Veintiuno Editores, S.A., 1995. p. 161-165. v. 1.

. Arquitectura y narratividad. Barcelona: Edicions

UPC, 2003.

SERENATAS ILUMINADAS. Disponível em: <https:// www.facebook.com/Serenata

Iluminada/>. Acesso em: 18 ago. 2016.

SHOOT THE SHIT. Disponível em: <http://www. shoottheshit.cc/>. Acesso em: 18 ago. 2016.

SMIC. Disponível em: <http://www2.portoalegre.

rs.gov.br/smic/default.php?. secao $=206>$. Acesso em: 16 ago. 2016.

VIVA CAIS MAUÁ. Disponível em: <http://

vivacaismaua.com.br/>. Acesso em: 16 mai. 2016.

Revista online do Departamento de Arquitetura e Urbanismo da Pontifícia Universidade Católica - 